\title{
THE SPECTRAL DECOMPOSITION METHOD FOR SOLVING THE LINDLEY INTEGRAL EQUATION AND RELATED NUMERICAL METHODS
}

DOI: $10.36724 / 2072-8735-2020-|4-|-49-55$

\author{
Lyudmila V. Lipilina, \\ Povolzhskiy State University of Telecommunications \\ and Informatics, Samara, Russia, \\ mila199 | |3@gmail.com
} Keywords: queuing system, average queue waiting
time, Lindley integral equation, Laplace transform,
hyperexponential distribution.

\begin{abstract}
In researching the traffic of modern computer networks and telecommunication networks, the methods of queuing theory are widely used. In turn, in studies of queuing systems (QS) of type G/G/I with arbitrary laws of the distribution of intervals between adjacent requirements in the input flow and service time, the spectral decomposition method (SDM) of solving the Lindley integral equation is used [I-3]. The basis of this method is the search for zeros and poles of the constructed spectral decomposition in the form of some fractional rational function involving numerical methods for determining the roots of polynomials. Moreover, the coefficients of the polynomial in the decomposition numerator are usually expressed in terms of the unknown parameters of the distribution laws used to describe the QS. Typically, these unknown parameters of the laws of distribution can be determined through the numerical characteristics of the analyzed traffic by the known method of moments. The purpose of this article is to illustrate in detail the spectral decomposition method as applied to QS H2/H2/I of type G/G/I with hyperexponential laws of second-order distributions and its relation to problems of numerical analysis. A characteristic feature of this distribution law is the possibility of its unambiguous description both at the level of the first two initial moments of time intervals, and at the level of three moments. The second-order hyper-exponential distribution law of $\mathrm{H} 2$ provides the coefficient of variation of time intervals , and starting from four, the $\mathrm{H} 2$ distribution law has a heavy tail, which is well suited for describing traffic with a heavy-tail distribution. The use of this law of higher order distribution in the method of spectral decomposition leads to an increase in the computational complexity of the problem. The proposed approach to the use of the spectral decomposition method allows us to determine, in addition to the average waiting time, other moments of waiting time. In the telecommunications standard, the concept of jitter is defined through the spread of waiting time around its average value. Then, the presented approach of applying the spectral decomposition method allows one to determine jitter through the second initial moment of waiting time. This refers to the practical applicability of queuing systems to the study of delays in telecommunication networks.
\end{abstract}

Information about author:

Lyudmila V. Lipilina, Povolzhskiy State University of Telecommunications and Informatics, graduate student of Department of Software and Management in Technical Systems, Samara, Russia

Для цитирования:

Липилина Л.В. Метод спектрального разложения решения интегрального уравнения линдли и связанные с ним численные методы // T-Comm: Телекоммуникации и транспорт. 2020. Том I4. №I. С. 49-55.

For citation:

Lyudmila V.L. (2020) The spectral decomposition method for solving the lindley integral equation and related numerical methods. T-Comm, vol. 14, no.I, PP. 49-55. (in Russian) 


\section{Introduction}

In [1], in the section of $\mathrm{G} / \mathrm{G} / 1$ systems of the general queuing theory, an incomplete formula for the average waiting time in the queue of requirements entering the system is given:

$$
W=\frac{\sigma_{a}^{2}+\sigma_{b}^{2}+(\bar{t})^{2}(1-\mathrm{c})^{2}}{2 \bar{t}(1-\mathrm{c})}-\frac{\overline{I^{2}}}{2 \bar{I}} .
$$

In [1] following notation is used:

$-\mathrm{c}$ is the system load factor;

- $л$ is the intensity of the incoming stream;

$-\mu$ is the intensity of service requirements,

- $\sigma_{a}$ and $\sigma_{b}$ - respectively, the standard deviation of the time intervals for the incoming flow and the service time;

$-\bar{I}, \overline{I^{2}}$ - the first two initial moments of a random variable of the idle period of system. These components of the above formula in the case of arbitrary $(\mathrm{G})$ distribution laws that determine the QS functioning process cannot be established in the general case. This formula unambiguously assumes that the average waiting time for requirements in the queue when recalculating variances for the coefficients of variation directly depends on the squares of the coefficients of variation of the time intervals for the incoming flow and the service time. In addition, computational experiments to determine the average waiting time using the example of QS with the laws of distributions of $\mathrm{H}_{2}$ confirm its dependence on the moments of time intervals above the second order.

A probabilistic mixture of two exponential distributions called the second-order hyperexponential distribution law $\mathrm{H}_{2}$ with a density function $f(t)=p \lambda_{1} e^{-\lambda_{1} t}+(1-p) \lambda_{2} e^{-\lambda_{2} t}$ is defined in [1], where it is noted that "the distribution law is threeparameter $\left(p, \pi_{1}, \pi_{2}>0\right)$ and allows the method of moments to approximate arbitrary distribution laws at the level of the first three initial moments". It was also used in $[8,9$, and 10] in the study of other QS.

For the study of $\mathrm{G} / \mathrm{G} / 1$ systems, as is known for example from [1], where "the Lindley integral equation is used. To write it, we introduce the following notation:

$-W(y)$ is the probability distribution function of the waiting time for requirements in the queue,

$-C(u)=P(\tilde{u}<u)$ is the probability distribution function of a random variable $\tilde{u}=\tilde{x}-\tilde{t}$, where, in turn $\tilde{x}$, is a random service time for a requirement, $\tilde{t}-$ a random variable is the time interval between requirements arrivals. Then one of the forms of the Lindley equation looks like this" [1]:

$$
W(y)=\left\{\begin{array}{cl}
\int_{-\infty}^{y} W(y-u) \mathrm{d} C(u), & y \geq 0 . \\
0, & y<0
\end{array}\right.
$$

From this notation, it can be seen that "the Lindley integral equation is valid only for non-negative values of the argument $y$ " [1].

In the course of illustrating the main points of the SDM of solving the Lindley integral equation, we retained the notation of the original [1], in which the notation and was introduced for the Laplace transforms of the density functions of the distribution of the intervals between the requirements $A^{*}(s)$ and the service time $B^{*}(s)$. "The SDM of solving the Lindley Integral Equation (LIE) consists in transforming the key expression $A^{*}(-s) \cdot B *(s)-1$ to the product of some two factors in the form of fractional rational functions. For definiteness, we will present this key expression of spectral decomposition in the form: $A^{*}(-s) \cdot B^{*}(s)-1=\psi_{+}(s) / \psi_{-}(s)$, where $\omega_{+}(s)$ and $\psi_{-}(s)$ are the components of the SDM" [1]. In each specific case of QS, these will be uniquely defined fractional rational functions $s$ that satisfy, according to [1], two general conditions (1) and (2):

1. In the case $\operatorname{Re}(\mathrm{s})>0, \psi_{+}(s)$ is an analytic function that does not contain zeros in this half-plane;

2. In the case $\operatorname{Re}(\mathrm{s})<D, \psi_{-}(s)$ it is an analytic function that does not contain zeros in this half-plane, where the constant $D>0$, for which

$$
\lim _{t \rightarrow \infty} \frac{a(t)}{e^{-D t}}<\infty
$$

Additionally, for the functions and the conditions must be met" [1]:

$$
\lim _{|s| \rightarrow \infty, \operatorname{Re}(s)>0} \frac{\psi_{+}(s)}{s}=1 ; \lim _{|s| \rightarrow \infty, \operatorname{Re}(s)<D} \frac{\psi_{-}(s)}{s}=-1 .
$$

The construction of these functions satisfying the above conditions (1) and (2) will be demonstrated below.

In the Russian-language scientific literature "instead of the spectral decomposition method for solving the Lindley integral equation, the factorization method and factorization components $\omega_{+}(z, t)$ and $\omega_{-}(z, t)$ are used" [2].

\section{Application of the spectral decomposition method}

to the study of QS with hyperexponential distributions

Consider the QS, which is formed by the laws of distributions:

- the density function of the intervals between requirements in the input flow has the form

$$
a(t)=p \lambda_{1} e^{-\lambda_{1} t}+(1-p) \lambda_{2} e^{-\lambda_{2} t},
$$

and the density function of the service time has the form

$$
b(t)=q \mu_{1} e^{-\mu_{1} t}+(1-q) \mu_{2} e^{-\mu_{2} t} .
$$

The Laplace transform of function (3) has the form:

$$
A^{*}(s)=p \frac{\lambda_{1}}{s+\lambda_{1}}+(1-p) \frac{\lambda_{2}}{s+\lambda_{2}},
$$

and functions (4)

$$
B *(s)=q \frac{\mu_{1}}{s+\mu_{1}}+(1-q) \frac{\mu_{2}}{s+\mu_{2}} .
$$

Then the spectral decomposition $A^{*}(-s) \cdot B^{*}(s)-1=\psi_{+}(s) / \psi_{-}(s)$, as the ratio of two fractional rational functions, will have the form:

$$
\frac{\psi_{+}(s)}{\psi_{-}(s)}=\left[p \frac{\lambda_{1}}{\lambda_{1}-s}+(1-p) \frac{\lambda_{2}}{\lambda_{2}-s}\right] \cdot\left[q \frac{\mu_{1}}{s+\mu_{1}}+(1-q) \frac{\mu_{2}}{s+\mu_{2}}\right]-1 .
$$


Convert this expression.

We imagine the first factor on the right side of the expression in square brackets in the form:

$$
\begin{aligned}
& {\left[p \frac{\lambda_{1}}{\lambda_{1}-s}+(1-p) \frac{\lambda_{2}}{\lambda_{2}-s}\right]=} \\
& =\frac{\lambda_{1} \lambda_{2}-\left[p \lambda_{1}+(1-p) \lambda_{2}\right] s}{\left(\lambda_{1}-s\right)\left(\lambda_{2}-s\right)}=\frac{a_{0}-a_{1} s}{\left(\lambda_{1}-s\right)\left(\lambda_{2}-s\right)},
\end{aligned}
$$

where the auxiliary parameters are equal to: $a_{0}=\lambda_{1} \lambda_{2}, a_{1}=p \lambda_{1}+(1-p) \lambda_{2}$.

Similarly, the second factor in square brackets can be represented as:

$$
\begin{aligned}
& {\left[q \frac{\mu_{1}}{\mu_{1}+s}+(1-q) \frac{\mu_{2}}{\mu_{2}+s}\right]=} \\
& =\frac{\mu_{1} \mu_{2}-\left[q \mu_{1}+(1-q) \mu_{2}\right] s}{\left(\mu_{1}+s\right)\left(\mu_{2}+s\right)}=\frac{b_{0}+b_{1} s}{\left(\mu_{1}+s\right)\left(\mu_{2}+s\right)},
\end{aligned}
$$

where the auxiliary parameters are equal to: $b_{0}=\mu_{1} \mu_{2}, b_{1}=q \mu_{1}+(1-q) \mu_{2}$.

After such simple transformations, the spectral decomposition can be represented as:

$$
\frac{\psi_{+}(s)}{\psi_{-}(s)}=\frac{\left(a_{0}-a_{1} s\right)\left(b_{0}+b_{1} s\right)-\left(\lambda_{1}-s\right)\left(\lambda_{2}-s\right)\left(\mu_{1}+s\right)\left(\mu_{2}+s\right)}{\left(\lambda_{1}-s\right)\left(\lambda_{2}-s\right)\left(\mu_{1}+s\right)\left(\mu_{2}+s\right)} .
$$

On the right side of the expansion, both in the numerator and the denominator, we have polynomials of the fourth degree. In the spectral decomposition method, we are interested in the polynomial in the numerator, which can be represented as you need to determine its zeros. In the spectral decomposition method, we are interested in the polynomial in the numerator, which can be represented as $-s^{4}+d_{2} s^{3}+d_{1} s^{2}+d_{0} s$ and then you need to determine its zeros. To do this, we determine its coefficients using the symbolic operations of the Mathcad mathematical package:

$$
\begin{aligned}
& \qquad \begin{aligned}
d_{0} & =a_{0} b_{1}-a_{1} b_{0}-a_{0}\left(\mu_{1}+\mu_{2}\right)+b_{0}\left(\lambda_{1}+\lambda_{2}\right), \\
d_{1} & =-a_{1} b_{1}-a_{0}-b_{0}+\left(\lambda_{1}+\lambda_{2}\right)\left(\mu_{1}+\mu_{2}\right)
\end{aligned} \\
& \text { and } d_{2}=\lambda_{1}+\lambda_{2}-\mu_{1}-\mu_{2} .
\end{aligned}
$$

They are expressed through so far unknown distribution parameters (3) and (4), which are subject to determination by the moment method. Now the ratio of two fractional rational functions $\psi_{+}(s) / \psi_{-}(s)$ can be represented as:

$$
\frac{\psi_{+}(s)}{\psi_{-}(s)}=\frac{s\left(s^{3}-d_{2} s^{2}-d_{1} s-d_{0}\right)}{\left(s-\lambda_{1}\right)\left(\lambda_{2}-s\right)\left(\mu_{1}+s\right)\left(\mu_{2}+s\right)} .
$$

It follows from the method of spectral (factorial) decomposition that such a decomposition exists and is unique.

For the completion of the spectral decomposition, it will be necessary to determine the roots of the equation

$$
s^{3}-d_{2} s^{2}-d_{1} s-d_{0}=0,
$$

satisfying together with this functions $\psi_{+}(s)$ and $\psi_{-}(s)$ this above conditions (1) and (2).
For this, it is necessary and sufficient "that the cubic equation (7) has two real negative roots (two complex conjugate roots with negative real parts), which for convenience we denote $-\sigma_{1}$ and $-\sigma_{2}$ and one positive root $\sigma_{3}$. The presence of the required roots is guaranteed by the uniqueness of the spectral decomposition" [1].

We will verify this using the example of equation (7). To do this, we study the sign of the lowest coefficient $d_{0}$ of the polynomial (7) according to the Vieta's formula. In the stationary mode of operation of the QS, its load factor must satisfy the condition:

$$
\rho=\frac{\bar{\tau}_{\mu}}{\bar{\tau}_{\lambda}}=\frac{\lambda_{1} \lambda_{2}}{\mu_{1} \mu_{2}} \frac{\left[\mu_{1}(1-q)+\mu_{2} q\right]}{\left[\lambda_{1}(1-p)+\lambda_{2} p\right]}<1 .
$$

The load factor here, as in simulation, is determined by the ratio of the average intervals: of the service time $\bar{\tau}_{\mu}$ and of the interval between requirements $\bar{\tau}_{\lambda}$ in the incoming flow.

The expression for the coefficient $d_{0}$ in expanded form has the form:

$$
d_{0}=-\lambda_{1} \lambda_{2}\left[\mu_{1}(1-q)+\mu_{2} q\right]+\mu_{1} \mu_{2}\left[\lambda_{1}(1-p)+\lambda_{2} p\right] .
$$

Now comparing the expressions for the lower coefficient $d_{0}$ and load $\rho$, we get that coefficient $d_{0}>0$. From the Vieta's formula it follows that the product of the three roots of the cubic equation $d_{0}=\sigma_{1} \sigma_{2} \sigma_{3}>0$, therefore, the required roots really exist.

"The components of the spectral decomposition method in the form of fractional rational functions $\psi_{+}(s)$ and $\psi_{-}(s)$ can be written according to conditions (1) and (2) in the form:

$$
\psi_{+}(s)=\frac{s\left(s+\sigma_{1}\right)\left(s+\sigma_{2}\right)}{\left(s+\mu_{1}\right)\left(s+\mu_{2}\right)}, \psi_{-}(s)=\frac{\left(s-\lambda_{1}\right)\left(\lambda_{2}-s\right)}{s-\sigma_{3}} .
$$

Then the function $\psi_{+}(s)$, includes only the negative real parts of the roots $-\sigma_{1}$ and $-\sigma_{2}$ of equation (7), and the function $\psi_{-}(s)$ - only the positive real root $\sigma_{3}$. Now we focus on the function $\psi_{+}(s)$ containing negative roots in the numerator and, when they are determined by Newton's numerical method, we adapt it to finding only negative roots" [1].

"Using the method of spectral decomposition, we determine the constant $K$ :

$$
K=\lim _{s \rightarrow 0} \frac{\psi_{+}(s)}{s}=\lim _{s \rightarrow 0} \frac{\left(s+\sigma_{1}\right)\left(s+\sigma_{2}\right)}{\left(s+\mu_{1}\right)\left(s+\mu_{2}\right)}=\frac{\sigma_{1} \sigma_{2}}{\mu_{1} \mu_{2}} .
$$

The constant $K$ in solving the problem means the probability that the next requirement arriving in the system, finds the system free" [1]. Next, through the function $\psi_{+}(s)$, we determine the Laplace transform $W^{*}(s)$ of the waiting time distribution function $W(y)$ :

$$
\Phi_{+}(s)=\frac{K}{\psi_{+}(s)}=\frac{\sigma_{1} \sigma_{2}\left(s+\mu_{1}\right)\left(s+\mu_{2}\right)}{s \mu_{1} \mu_{2}\left(s+\sigma_{1}\right)\left(s+\sigma_{2}\right)} .
$$


Through it, we express the Laplace transform of the probability density function of the waiting time probability $s \cdot \Phi_{+}(s)$ "

[1]. Finally, the Laplace transform $W^{*}(s)$

$$
W^{*}(s)=\frac{\sigma_{1} \sigma_{2}\left(s+\mu_{1}\right)\left(s+\mu_{2}\right)}{\mu_{1} \mu_{2}\left(s+\sigma_{1}\right)\left(s+\sigma_{2}\right)} .
$$

Based on the properties of the Laplace transform, we define its first derivative

$$
\begin{aligned}
& \frac{d W^{*}(s)}{d s}=\frac{\sigma_{1} \sigma_{2}\left(2 s+\mu_{1}+\mu_{2}\right) \mu_{1} \mu_{2}\left(s+\sigma_{1}\right)\left(s+\sigma_{2}\right)}{\mu_{1}^{2} \mu_{2}^{2}\left(s+\sigma_{1}\right)^{2}\left(s+\sigma_{2}\right)^{2}}- \\
& -\frac{\sigma_{1} \sigma_{2}\left(s+\mu_{1}\right)\left(s+\mu_{2}\right) \mu_{1} \mu_{2}\left(2 s+\sigma_{1}+\sigma_{2}\right)}{\mu_{1}^{2} \mu_{2}^{2}\left(s+\sigma_{1}\right)^{2}\left(s+\sigma_{2}\right)^{2}}
\end{aligned}
$$

and find the average waiting time for requirements in the queue

$$
\begin{aligned}
& -\left.\frac{d W^{*}(s)}{d s}\right|_{s=0}=\frac{\sigma_{1} \sigma_{2} \mu_{1}^{2} \mu_{2}^{2}\left(\sigma_{1}+\sigma_{2}\right)-\sigma_{1}^{2} \sigma_{2}^{2} \mu_{1} \mu_{2}\left(\mu_{1}+\mu_{2}\right)}{\mu_{1}^{2} \mu_{2}^{2} \sigma_{1}^{2} \sigma_{2}^{2}}= \\
& =\frac{\sigma_{1}+\sigma_{2}}{\sigma_{1} \sigma_{2}}-\frac{\mu_{1}+\mu_{2}}{\mu_{1} \mu_{2}}=\frac{1}{\sigma_{1}}+\frac{1}{\sigma_{2}}-\frac{1}{\mu_{1}}-\frac{1}{\mu_{2}} .
\end{aligned}
$$

This the final calculation formula for the average waiting time for QS $\mathrm{H}_{2} / \mathrm{H}_{2} / 1$ can be represented as:

$$
W=\frac{1}{\sigma_{1}}+\frac{1}{\sigma_{2}}-\frac{1}{\mu_{1}}-\frac{1}{\mu_{2}}
$$

where $\sigma_{1}$ and $\sigma_{2}$ there are absolute values of the found negative roots $-\sigma_{1},-\sigma_{2}$.

From expression (8) for the spectral expansion of the probability density function of the waiting time, it is also possible to determine the initial moments of the second, third and higher orders for the waiting time. Determining the second derivative of $W^{*}(s)$, we find the second initial moment of the waiting time:

$$
\begin{aligned}
& \overline{W^{2}}=\frac{d^{2} W^{*}(s)}{d s^{2}}=\frac{2}{\mu_{1} \mu_{2}}-\frac{2}{\sigma_{1} \sigma_{2}}- \\
& -\frac{2\left(\sigma_{1}+\sigma_{2}\right)}{\mu_{1} \mu_{2} \sigma_{1}^{2} \sigma_{2}^{2}}\left[\sigma_{1} \sigma_{2}\left(\mu_{1}+\mu_{2}\right)-\mu_{1} \mu_{2}\left(\sigma_{1}+\sigma_{2}\right)\right]
\end{aligned},
$$

through which we express the variance of this random variable. Recalling that the concept of "delay jitter" in telecommunications according to the standard [7] is defined as the spread of the waiting time from its average value $W$, the delay jitter can be determined through the variance. This fact can be considered as a practical application of the theory of queuing for the analysis of teletraffic of telecommunication networks.

\section{Determination of parameters of distribution laws using}

\section{the first two initial moments of time intervals}

For practical calculations of the average waiting time for requirements in the queue according to formula (9), it is necessary to determine the parameters of the distribution laws that describe the operation of the QS. For this, we again use the properties of the Laplace transform and determine the initial moments for distributions (3) and (4). For distribution (3) we have:

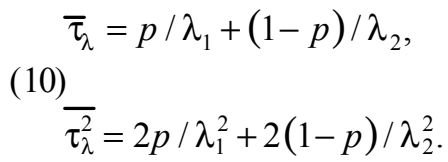

Because distributions (3) and (4) include three parameters each, to these two equations of moments we add the third equation (12) with respect to the square of the coefficient of variation of the intervals of receipts:

$$
c^{2}=\left[\overline{\tau_{\lambda}^{2}}-\left(\tau_{\lambda}\right)^{2}\right] /\left(\tau_{\lambda}\right)^{2} .
$$

At the same time, the third equation (12) relates equations (10) and (11) to each other. Now, having solved the system of three nonlinear equations $(10)-(12)$, we will determine the distribution parameters (3) $\lambda_{1}, \lambda_{2}, p$ unknown so far. Since the not complete formula of the queuing theory given at the very beginning includes the squares of the coefficients of variations, this approach is completely valid. In the future, the coefficients of variation will be used as input parameters of the task of calculating the average waiting time of requirements in the queue.

Now we indicate the technique for solving systems of nonlinear equations (10) - (12). Using the substitution method for solving systems of equations, we set as parameters $\pi_{1}$ and $\pi_{2}$ :

$$
\lambda_{1}=2 p / \tau_{\lambda}, \quad \lambda_{2}=2(1-p) / \tau_{\lambda}
$$

so that they satisfy the equation of moments $(10)$ and we substitute them in (12) taking into account (11), (12). Then we obtain an equation of the fourth degree with respect to the parameter $p$. Discarding two trivial solutions $p=0, p=1$ in this equation, we reduce the degree of the equation to two and solving this equation with respect to the parameter $p$, we obtain two roots:

$$
p=\frac{1}{2}\left(1 \pm \sqrt{\frac{c_{\lambda}^{2}-1}{c_{\lambda}^{2}+1}}\right) .
$$

For definiteness, in further calculations we will use the largest root. Therefore, the hyperexponential distribution law of $\mathrm{H}_{2}$ can be described at the level of the first two moments and it provides a coefficient of variation $c_{\tau}$ from unity to ?

We will do the same with distribution (4), then its unknown parameters will take the form:

$$
\mu_{1}=2 q / \bar{\tau}_{\mu}, \mu_{1}=2(1-q) / \bar{\tau}_{\mu}, q=\frac{1}{2}\left(1 \pm \sqrt{\frac{c_{\mu}^{2}-1}{c_{\mu}^{2}+1}}\right) .
$$

Consider an example. For definiteness, we take the load factor of the QS equal: $\rho=\bar{\tau}_{\mu} / \bar{\tau}_{\lambda}=0,9$. Note that the load factor here is determined, as in simulation systems, by the ratio of the average intervals. We set the average service time in QS equal $\tau_{\mu}=\mu^{-1}=1$, then the average interval between receipts will be equal $\bar{\tau}_{\lambda}=10 / 9$. Additionally, as input parameters we take the coefficients of variation of time intervals equal to two: $c_{\lambda}=c_{\mu}=2$. A description of the distribution law using the first two initial moments gives the following values of the distribution parameters (3) and (4) when rounding the results: $p \approx 0,887$, $\lambda_{1} \approx 1,597, \quad \lambda_{2} \approx 0,203, \quad q \approx 0,887, \quad \mu_{1} \approx 1,775, \quad \mu_{2} \approx 0,225$. Thus, all parameters of distributions (3) and (4) are uniquely determined. 
Now it remains to determine the coefficients of equation (7) and for them we obtain the following results:

$d_{0} \approx 0,014 ; d_{1} \approx 0,572 ; d_{2}=-0,201$. The negative roots of this polynomial we need are determined using the Newton method, which gives: $-\sigma_{1} \approx-0,852,-\sigma_{2} \approx-0,025$. The average waiting time for requirements in the queue $\mathrm{W}$ according to the calculation formula (10) for the considered example is equal to $W \approx 36,202$ time units.

The results of computational experiments obtained in the Mathcad package for the average latency in QS $\mathrm{H}_{2} / \mathrm{H}_{2} / 1$ are presented in table 1. Here we consider the cases of small $(\mathrm{c}=0,1)$, medium $(c=0,5)$ and high load $(c=0,9)$ with service time $\bar{\tau}_{\mu}=1$ and coefficient of variation of intervals between receipt of requirements $c_{\lambda}$ and service time $c_{\mu}$ equal to $2,4,8$.

Table 1

\section{The results of computational experiments for $\mathrm{QS}_{2} / \mathrm{H}_{2} / 1$}

\begin{tabular}{ccc}
\multicolumn{2}{c}{ Input parameters for QS } & $\begin{array}{c}\text { Average waiting time } \\
\text { for } \mathrm{QS} \mathrm{H}_{2} / \mathrm{H}_{2} / 1\end{array}$ \\
$\mathrm{c}$ & $\left(c_{\lambda}, c_{\mu}\right)$ & \\
0,1 & $(2,2)$ & 0,452 \\
& $(4,4)$ & 1,781 \\
& $(8,8)$ & 7,110 \\
0,5 & $(2,2)$ & 4,039 \\
& $(4,4)$ & 16,131 \\
0,9 & $(8,8)$ & 64,178 \\
& $(2,2)$ & 36,201 \\
& $(4,4)$ & 144,832 \\
& $(8,8)$ & 577,861
\end{tabular}

\section{Determination of the parameters of distribution laws} using the first three initial moments of time intervals

Because the $\mathrm{H}_{2}$ distribution under consideration contains three parameters, we will approximate the distribution law using the first three initial moments of time intervals and compare the results with the data obtained using the first two initial moments. Using the Laplace transforms of functions (5) and (6) will give the following expressions for the moments of time intervals of the third order:

- for input flow intervals

$\overline{\tau_{\lambda}^{3}}=6 p / \lambda_{1}^{3}+6(1-p) / \lambda_{2}^{3}$,

- for service time

$$
\overline{\tau_{\mu}^{3}}=6 q / \mu_{1}^{3}+6(1-q) / \mu_{2}^{3} \text {. }
$$

Now, in the example considered above, we add the expression for the third moment as the third equation. We define it through the asymmetry coefficient and take for example $A_{S \lambda}=A_{S \mu}=4$, more than that of the Poisson flow. Now the input parameters for the second and third initial moments will change and become equal; $\overline{\tau_{\lambda}^{2}}=5 \cdot(10 / 9)^{2}, \overline{\tau_{\lambda}^{3}}=45 \cdot(10 / 9)^{3}$, $\overline{\tau_{\mu}^{2}}=5, \overline{\tau_{\mu}^{3}}=45$. Then the equations of moments take the form:

$$
\begin{aligned}
& \left\{\begin{array}{c}
p / \lambda_{1}+(1-p) / \lambda_{2}=10 / 9 \\
2 p / \lambda_{1}^{2}+2(1-p) / \lambda_{2}^{2}=5 \cdot(10 / 9)^{2}, \\
6 p / \lambda_{1}^{3}+6(1-p) / \lambda_{2}^{3}=45 \cdot(10 / 9)^{3}
\end{array}\right. \\
& \left\{\begin{array}{c}
q / \mu_{1}+(1-q) / \mu_{2}=1 \\
2 q / \mu_{1}^{2}+2(1-q) / \mu_{2}^{2}=5 . \\
6 q / \mu_{1}^{3}+6(1-q) / \mu_{2}^{3}=45
\end{array}\right.
\end{aligned}
$$

The solution of these systems of nonlinear equations in the Mathcad mathematical package gives the desired distribution parameters (3) and (4). The solution for system (14) is: $p \approx 0,739, \lambda_{1} \approx 3,306, \lambda_{2} \approx 0,294$, and for system (15), the solution is: $q \approx 0,739, \mu_{1} \approx 3,673, \mu_{2} \approx 0,327$.

The coefficients of equation (7) for such values of the distribution parameters (3) and (4) are equal to: $d_{0} \approx 0,130$; $d_{1} \approx 5,172 ; d_{2} \approx-0,40$, and its negative roots: $-\sigma_{1} \approx-2,471$, $-\sigma_{2} \approx-0,025$.

Therefore, conditions (1) and (2) for the spectral decomposition method are fulfilled (in this case we have two real negative roots and one positive root). We determine the average waiting time by the calculation formula (9): $W \approx 37,051$ units of time, which is $2.35 \%$ more than in the first case when using only two initial moments.

In $[5,6]$, necessary and sufficient conditions for the existence of a unique solution to systems of three equations of moments similar to systems (14) and (15) are given in the form of a constraint

$$
\overline{\tau_{j}^{3}} \cdot \overline{\tau_{j}} \geq 1,5 \cdot \overline{\tau_{j}^{2}}
$$

As computational experiments on this system have shown, the approximation of the distribution law at the level of the first two moments underestimates the average waiting time in the queue in the system, compared with the three-moment approximation. This can easily be explained by the difference in the distribution parameters for these two density functions, as shown by their values above. In addition to this, Fig. 1 shows their graphs to confirm this fact [8].

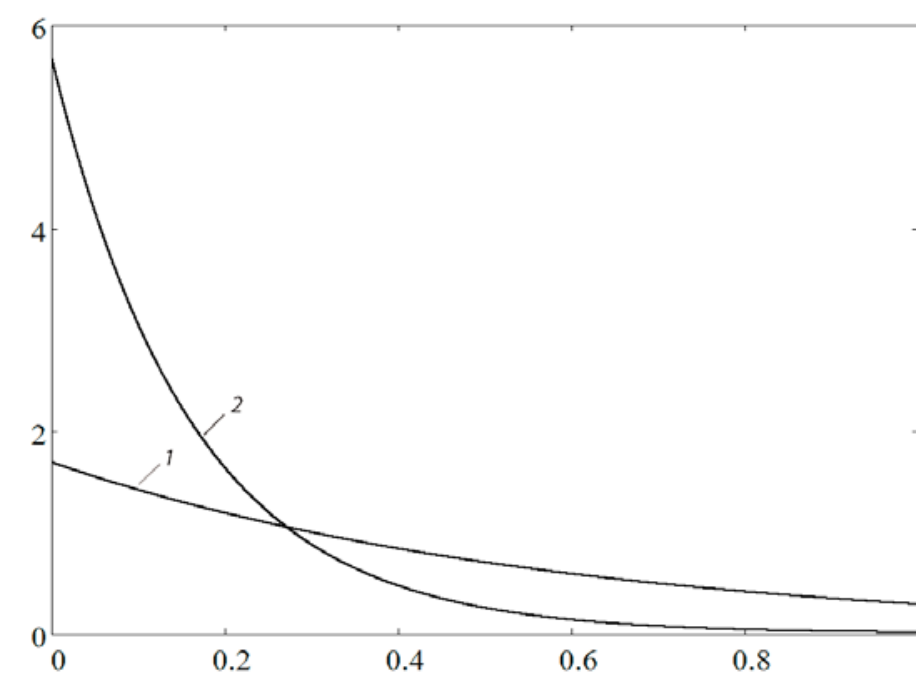

Fig. 1. Graphs of the distribution density function (4): 1 - using two initial moments; 2 - using three initial moments 


\section{Conclusions}

The article presents the spectral decomposition obtained by the classical method of solving the Lindley integral equation for QS formed by two hyperexponential distributions and a solution for the average waiting time for this system. In this case, the application of the method of spectral decomposition together with numerical methods for finding the negative roots of polynomials and finding positive solutions to systems of two and three nonlinear equations is succes sively illustrated.

It is shown that the use of the proposed approach, in addition to the average waiting time, also allows you to determine the moments of waiting time above the first. Then, through the second moment (variance) of the waiting time, it is possible to determine the jitter value in telecommunication networks as delay fluctuations around its average value. Therefore, this approach can be used in the modern theory of teletraffic as a practical application. To do this, you need to know the moment characteristics (two or three first initial moments) of the time intervals of the incoming traffic.

Because the $\mathrm{H}_{2}$ distribution includes three parameters, it allows using the method of moments to approximately describe arbitrary input distributions using the first three initial moments. The presented method of approximating the $\mathrm{H}_{2}$ distribution law at the level of the first two initial moments shows underestimated results in the average waiting time compared to the approximation of the $\mathrm{H}_{2}$ distribution law using three initial moments.

\section{References}

1. Kleinrock, L. (1979). Teoriya massovogo obsluzhivaniya [Queuing theory] Translated by V.I. Neiman. Moscow. Mashinostroeinie Publ. (in Russian)
2. Bocharov P.P., Pechinkin A.V. (1995) Teoriya massovogo obsluzhivaniya [Queuing theory]. Moscow: RUDN Publ. (in Russian)

3. Tarasov V.N., Kartashevskiy I.V., Lipilina L.V. (2015) Issle dovanie zaderzhki v sisteme G/G/1 [Research of the delay in G/G/1 system] Infokommunikacionnye tehnologii, v.13, I. 2, pp. 153-159. (in Russian)

4. Vishnevskiy V.M. (2003) Teoreticheskie osnovyi proektirovaniya kompyuternyih setey [Theoretical Foundations of Computer Network Design] M.: Tehnosfera. (in Russian)

5. Myskja A. (1991) An improved heuristic approximation for the GI/GI/1 queue with bursty arrivals. Teletraffic and datatraffic in a Period of Change, ITC-13. Elsevier Science Publishers, pp. 683-688.

6. Whitt W. (1982) Approximating a point process by a renewal process: two basic methods. Operation Research, v.30, no. 1, pp. 125-147.

7. https://tools.ietf.org/html/rfc3393. RFC 3393 IP Packet Delay Variation Metric for IP Performance Metrics (IPPM) (accessed: 26.02.2016).

8. Tarasov V.N., Bakhareva N.F., Lipilina L.V. (2016) Matematicheskaya model teletrafika na osnove sistemy $\mathrm{G} / \mathrm{M} / 1$ i rezul'taty vychislitel'nyh eksperimentov [Mathematical model of teletraffic on the based $\mathrm{G} / \mathrm{M} / 1$ system and results of computational experiment] Informacionnye technologï, vol. 22, no.2, pp. 121-126. (in Russian)

9. Tarasov V.N., Gorelov G.A., Ushakov Y.A. (2014) Vosstanovlenie momentnyh harakteristik raspredeleniya intervalov vremeni mezhdu paketami vhodyaschego trafika [Restoring moment distribution characteristics interval between packets of incoming traffic] Informacionnye technologii, no.2, pp. 40-44. (in Russian)

10. Tarasov V.N., Bakhareva N.F., Lipilina L.V. (2016) Avtomatizaciya rascheta harakteristik sistem massovogo obsluzhivaniya dlya shirokogo diapazona izmeneniya ih parametrov [Automation for calculating characteristics queuing system for a wide range changing their parameters] Informacionnye tekhnologii. no.12, pp. 952-957. (in Russian) 


\section{МЕТОД СПЕКТРАЛЬНОГО РАЗЛОЖЕНИЯ РЕШЕНИЯ ИНТЕГРАЛЬНОГО УРАВНЕНИЯ ЛИНДЛИ И СВЯЗАННЫЕ С НИМ ЧИСЛЕННЫЕ МЕТОДЫ}

Липилина Людмила Владимировна, Поволжский государственный университет телекоммуникаций и информатики, 2. Самара, Россия, mila1991/3@gmail.com

\section{Аннотация}

При исследовании трафика современных компьютерных сетей и сетей телекоммуникаций широко используются методы теории массового обслуживания. В свою очередь, в исследованиях систем массового обслуживания (CMO) типа G/G/I с произвольными законами распределений интервалов между соседними требованиями во входном потоке и времени обслуживания, часто применяется метод спектрального разложения (МСР) решения интегрального уравнения Линдли [I-3]. В основе этого метода лежит поиск нулей и полюсов построенного спектрального разложения в виде некоторой дробно-рациональной функции с привлечением численных методов для определения корней многочленов. При этом коэффициенты многочлена в числителе разложения выражаются через неизвестные параметры используемых для описания СМО законов распределений. Обычно эти неизвестные параметры законов распределений могут быть определены через числовые характеристики анализируемого трафика известным методом моментов. Цель данной статьи заключается в подробной иллюстрации метода спектрального разложения применительно к CMO $\mathrm{H}_{2} / \mathrm{H}_{2} / \mathrm{I}$ типа $\mathrm{G} / \mathrm{G} / \mathrm{I}$ с гиперэкспоненциальными законами распределений второго порядка и его связи с задачами численного анализа. Характерной особенностью этого закона распределения является возможность его однозначного описания как на уровне двух первых моментов временных интервалов, так и на уровне трех моментов. Гиперэкспоненциальный закон распределения второго порядка $\mathrm{H}_{2}$ обеспечивает коэффициент вариации временных интервалов $\mathrm{c}_{\tau} \geq \mathrm{I}$, а начиная с четырех, закон распределения $\mathrm{H} 2$ имеет тяжелый хвост, что хорошо подходит для описания трафика с тяжелохвостным распределением. Использование этого закона распределения большего порядка в методе спектрального разложения приводит к возрастанию вычислительной сложности задачи. Предлагаемый подход к использованию метода спектрального разложения позволяет определить кроме среднего времени ожидания и другие моменты времени ожидания. В стандарте по телекоммуникациям понятие джиттера определено через разброс времени ожидания вокруг его среднего значения. Тогда представленный подход применения метода спектрального разложения позволяет определить джиттер через второй момент времени ожидания.

Ключевые слова: система массового обслуживания, среднее время ожидания в очереди, интегральное уравнение Линдли, преобразование Лапласа, гиперэкспоненциальное распределение.

\section{Литература}

І. Клейнрок Л. Теория массового обслуживания / Пер. с англ. под ред. В.И. Неймана М.: Машиностроение, 1979. 432 с.

2. Бочаров П.П., Печинкин А.В. Теория массового обслуживания: Учебник.: Изд-во РУДН, 1995. 529 с.

3. Тарасов В.Н., Карташевский И.В., Липилина Л.В. Исследование задержки в системе G/G// // Инфокоммуникационные технологии. Т. 13. №2. 2015. C. 153-159.

4. Вишневский В.М. Теоретические основы проектирования компьютерных сетей. М.: Техносфера, 2003. 512 c.

5. Myskja A. An improved heuristic approximation for the GI/GI/I queue with bursty arrivals // Teletraffic and datatraffic in a Period of Change, ITC-I3. Elsevier Science Publishers, 1991, pp. 683-688.

6. Whitt W. Approximating a point process by a renewal process: two basic methods // Operation Research, v. 30, no.I, I982, pp. I25-I47.

7. HTTPS://tools.ietf.org/html/rfc3393. RFC 3393 IP Packet Delay Variation Metric for IP Performance Metrics (IPPM) (дата обращения: 26.02.20I6).

8. Тарасов В.Н., Бахарева Н.Ф., Липилина Л.В. Математическая модель телетрафика на основе системы G/M/I и результаты вычислительных экспериментов // Информационные технологии. Т. 22. №2. 2016. С. I2I-I26.

9. Тарасов В.Н., Горелов Г.А., Ушаков Ю.А. Восстановление моментных характеристик распределения интервалов между пакетами входящего трафика // Инфокоммуникационные технологии. №2. 20I4. С. 40-44.

10. Тарасов В.Н., Бахарева Н.Ф., Липилина Л.В. Автоматизация расчета характеристик систем массового обслуживания для широкого диапазона изменения их параметров // Информационные технологии. Т. 22. №12. 2016. С. 952-957.

Информация об авторе:

Липилина Людмила Владимировна, Поволжский государственный университет телекоммуникаций и информатики, аспирант кафедры ПОУТС, 2. Самара, Россия 